\title{
Grupo de estudos Paideia: uma PROPOSTA de FORMAÇÃo humANista NA UNIVALI ${ }^{1}$
}

\section{Paideia study group: a proposal for humanistic formation at Univali}

\section{Grupo de estudios Paideia: una propuesta de formación humanista en Univali}

\author{
Tiago Mendonça dos Santos ${ }^{2}$ \\ Bruna Manuela Adriano ${ }^{3}$ \\ José Everton da Silva ${ }^{4}$
}

\begin{abstract}
RESUMO
O Grupo de Pesquisa e Extensão Paideia é um projeto desenvolvido na Univali que tem por objetivo formar jovens com base no modelo humanista clássico, atualizado às necessidades do mundo de hoje. Para tanto, o Grupo estimula os acadêmicos participantes ao estudo, à pesquisa científica, às práticas de extensão, bem como à inserção no mercado de trabalho. Assim, ao trabalhar com jovens estudantes universitários, acaba beneficiando não somente a eles, mas também a toda a comunidade acadêmica e também à comunidade municipal. As atividades do Grupo Paideia se iniciaram no campus de Itajaí da Univali, onde o Grupo já conta com mais de 10 anos, desde quando se iniciou como um Grupo de Estudos da obra Paideia: a formação do homem grego, de Werner Jaeger. O presente artigo tem por objetivo relatar as atividades realizadas no projeto de implantação de um Grupo de Estudos Paideia na região da Grande Florianópolis, atingindo os campi de São José e Biguaçu e Unidade do Kobrasol, todos da Univali. O projeto foi desenvolvido durante dois anos com fomento da Univali. Nesse período, o Grupo de Estudos se estabeleceu, realizando-se encontros semanais para estudo da Paideia. Além disso, foram também realizados eventos internos e externos ao Grupo. Com o término do projeto, ressalta-se que a semente do Grupo Paideia foi plantada, o que possibilitará o desenvolvimento das demais atividades atualmente realizadas com reconhecido sucesso em Itajaí.
\end{abstract}

Palavras-chave: Paideia; formação; humanismo; indivíduo; sociedade.

\begin{abstract}
The Research and Extension Group Paideia is a project developed in Univali that aims to train youngsters based on the classical humanist model, updated to the needs of today's world. In order to do this, the Group encourages participating students to study, do scientific research, perform extension practics and participate in the labor market. So, working with young universitary students ends up benefiting not only themselves but also the entire academic community and also to the community hall. The Paideia Group's activities began on the campus Univali Itajaí, where the Group is already over 10 years old since it started as a Study Group of the Werner Jaeger's book Paideia: the formation of the Greek man. This article aims to report the activities carried out to implement Paideia Study Group in the Great Florianópolis Region, reaching the campuses of San Jose and Biguaçu and the Kobrasol Unit, all of Univali. The project was developed during over two years with the encouragement of Univali. During this period, the Study Group
\end{abstract}

\footnotetext{
${ }_{1}$ Projeto desenvolvido com auxílio do Programa de Bolsas de Extensão da Universidade do Vale do Itajaí (Univali).

2 Bacharel em Direito pela Univali. Bolsista de extensão. R: Profa. Cremilde de Oliveira, 285, Jardim Atlântico, Florianópolis, CEP: 88095-560. E-mail: tiagomendonca@univali.br. Telefone: (48) 9631-0004.

3 Bacharel em Direito pela Universidade do Vale do Itajaí (Univali). Bolsista de extensão. E-mail: bruna.adriano@univali.br

${ }^{4}$ Mestre em Desenvolvimento Regional pela Universidade Regional de Blumenau (Furb). Professor orientador. E-mail: caminha@univali.br
} 
has been established, performing weekly meetings to study Paideia. Moreover, events inside and outside the Group werealso conducted. With the end of the project, it is noteworthy that the seed was planted for a Paideia Group, which will enable the development of other activities currently carried out with recognized success in Itajaí.

Keywords: Paideia; formation; humanism; individual; society.

\section{RESUMEN}

El Grupo de Investigación y Extensión Paideia es un proyecto desarrollado en Univali cuyo objetivo es formar jóvenes con base en el modelo humanista clásico, actualizado a las necesidades del mundo de hoy. Para ello, el Grupo estimula a los académicos participantes al estudio, a la investigación científica, a las prácticas de extensión, así como a la inserción en el mercado de trabajo. Así, el trabajar con jóvenes estudiantes universitarios acaba beneficiando no solamente a ellos, sino también a toda la comunidad académica y también a la comunidad municipal. Las actividades del Grupo Paideia se iniciaron en el campus de Itajaí de Univali, donde el Grupo ya cuenta con más de 10 años desde que se inició como un Grupo de Estudios de la obra Paideia: la formación del hombre griego, de Werner Jaeger. El presente artículo tiene por objetivo relatar las actividades realizadas en el proyecto de implementación del Grupo de Estudios Paideia en la región de Grande Florianópolis, alcanzando los campi de São José y Biguaçu y la Unidad del Kobrasol, todos de Univali. El proyecto fue desarrollado durante dos años com apoyo de Univali. En este período el Grupo de Estudos quedó establecido, realizándose encuentros semanales para el estudio de Paideia. Además de eso, también fueron realizados eventos internos y externos al Grupo. Con el término del proyecto se resalta que la semilla del Grupo Paideia fue plantada, lo que posibilitará el desarrollo de las demás actividades actualmente realizadas con reconocido éxito en Itajaí.

Palabras clave: Paideia; formación; humanismo; individuo; sociedad.

Introdução

O Grupo de Estudos Paideia é um espaço de formação humanista criado dentro da Universidade do Vale do Itajaí (Univali). Constituído junto ao Curso de Direito da Univali - campus de Itajaí, em seus quase dez anos de existência, o grupo se expandiu de modo a não somente atender aos acadêmicos de Direito, nem somente aos das Ciências Sociais e das Relações Internacionais (cursos que compõem o Centro de Ciências Sociais e Jurídicas da Univali - Cejurps), mas a toda a comunidade acadêmica do referido campus.

Como fruto desse crescimento vertiginoso, que faz com que alunos de diversos cursos da Universidade participem do projeto, tem-se a construção do Grupo de Pesquisa e Extensão Paideia, que, pelo norte fornecido pelo Grupo de Estudos, atua nas áreas da pesquisa científica, da extensão universitária - que, nesse sentido, tem beneficiado jovens de comunidades carentes próximas à Universidade, bem como estudantes da rede pública de ensino com a visão de formação humana do Grupo Paideia - e do incentivo à inserção no mercado de trabalho.

Tendo em vista o sucesso do desenvolvimento deste projeto dentro do campus de Itajaí, propôs-se sua expansão para os campi de São José e Biguaçu e para a Unidade do Kobrasol da Univali, todos situados na região da Grande Florianópolis.

Deste modo, o objetivo deste projeto de extensão foi, em um primeiro momento, a implantação do Grupo de Estudos Paideia dentro dessa região, a partir do campus de São José da Univali, que inclui a Unidade do Kobrasol (situada em um outro bairro do mesmo município), de modo que, com o crescimento do projeto, as demais atividades atualmente elaboradas no campus de Itajaí possam vir a beneficiar também toda a comunidade da Grande Florianópolis.

O público a ser alcançado por este projeto, em um primeiro momento, foi a comunidade acadêmica dos campi e da unidade aca- 
dêmica acima enumerados, envolvendo-se assim os alunos, professores e funcionários da Univali, mas também a toda a comunidade interessada em participar do projeto.

No presente artigo demonstra-se a proposta de formação do Grupo Paideia que se buscou implementar na nova localidade e os primeiros resultados obtidos no processo de sua construção. Trata-se de um breve relato da experiência dos dois bolsistas que desenvolveram o projeto e dos resultados obtidos até o momento.

\section{A proposta de formação do grupo de estudos Paideia}

\section{O Grupo de Estudos Paideia tem o} seu desenvolvimento creditado à constatação por parte do Prof. Dr. Josemar Soares da necessidade de se formar os acadêmicos do Curso de Direito de uma maneira mais completa do que a mera excelência na transmissão dos conhecimentos necessários para a graduação em Ciência Jurídica. Era preciso também preparar os discentes para suas próprias vidas, bem como para a vivência em sociedade, afinal, este é o espírito que deu origem à universitas.
Imbuídos do espírito do humanismo clássico grego, um grupo de professores da Univali, dentre estes o Prof. Dr. Josemar Soares e o Prof. MSc. José Everton da Silva, orientador deste projeto, apoiados pelo Instituto $\mathrm{Vis}^{5}$, criaram um Grupo de Estudos, com a proposta de estudar a obra Paideia: a formação do homem grego, do filólogo alemão Werner Jaeger. Os estudos dessa obra duraram mais de três anos, durante os quais, em homenagem à obra, o grupo acabou sendo batizado como Grupo de Estudos Paideia 6 .

Todavia, o termo Paideia não é somente a homenagem do Grupo à primeira obra estudada, mas também traduz de maneira precisa qual é sua proposta. Traduzir o termo Paideia para as línguas contemporâneas é uma tarefa extremamente complicada, pois este termo, oriundo do grego clássico, abarca ao mesmo tempo a noção de educação, formação, cultura, literatura e educação, tal como destaca Jaeger ${ }^{7}$. Os romanos traduziram esse espírito por humanitas; já na atualidade, o termo que mais se aproxima desta noção é Bildung ${ }^{8}$, palavra do idioma alemão9 .

Tem-se, assim, que o espírito do Grupo de Estudos é fazer uma Paideia com os seus participantes, formá-los, prepará-los, de maneira integral para os desafios da vida no mundo contemporâneo.

\footnotetext{
${ }_{5}$ Mais informações disponíveis em:<http://www.visconsultoria.com.br $>$.

${ }^{6}$ Destaca-se que, após o estudo da Paideia em Itajaí, foram também objeto de estudo do Grupo as obras A república, de Platão, Ética a Nicômaco, Política, Metafísica e Arte retórica, de Aristóteles, e a obra Confissóes, de Santo Agostinho. No ano de 2009, outros dois grupos de estudos foram criados, o Grupo de Estudos em Literatura e Sociedade e o Grupo de Estudos em Psicologia Organizacional. O primeiro já estudou até o momento as obras: Hamlet, de William Shakespeare, Vidas secas, de Graciliano Ramos e Viagem ao centro da Terra, de Julio Verne. O Grupo de estudos em Psicologia Organizacional, por sua vez, centrou seus estudos na obra O diário de negócios de Maslow até o momento.

7 Conforme Jaeger: "Paideia, a palavra que serve de título a esta obra, não é apenas um nome simbólico; é a única designação exata do tema histórico nela estudado. Este tema é, de fato, difícil de definir: como outros conceitos de grande amplitude (por exemplo os de filosofia ou cultura), resiste a deixar-se encerrar numa fórmula abstrata. $O$ seu conteúdo e significado só se revelam plenamente quando lemos a sua história e lhes seguimos o esforço para conseguirem plarmar-se na realidade. [... . Não se pode evitar o emprego de expressões modernas como civilização, cultura, tradição, literatura ou educação; nenhuma delas, porém, coincide realmente com o que os Gregos entendiam por Paideia. Cada um daqueles termos se limita a exprimir um aspecto daquele conceito global, e, para abranger o campo total do conceito grego, teríamos de empregá-los todos de uma só vez" (JAEGER, 2003, p. 1) (grifos do autor).

8 Sobre o assunto, considera Jaeger: "A palavra alemã Bildung (formação, configuração) é a que designa do modo mais intuitivo a essência da educação no sentido grego e platônico" (JAEGER, 2003, p. 13) (grifo do autor).

9 De uma maneira mais aproximativa, preferiu-se traduzir esta riquíssima expressão como formação, tal como adotou o tradutor da obra para a língua portuguesa.
} 
A noção de crise da existência humana começou a ser denunciada pelos filósofos chamados de existencialistas. Kierkegaard (1988) e Nietzsche (1998), considerados os seus precursores, um pelo caminho da religião, outro pela negação desta, consideravam a importância da afirmação do indivíduo como elemento primordial para o sucesso na vida. Após estes, com Heidegger (2005) e, mais ainda, com Sartre (1997), há a denúncia dessa situação em que o ser humano vive, se relaciona, inclusive faz ciência sem ter um objetivo próprio por trás de tudo isso.

O movimento da Psicologia Humanista pode ser destacado como uma frente que buscou dar uma solução a esses dilemas. Autores como Carl Rogers (1990), Rollo May (200?) e Abraham Maslow (199?) buscaram desenvolver uma psicologia que, mais do que se preocupar com os desvios da psique humana (psicanálise) ou entender o comportamento humano (behaviorismo), servisse de meio para orientar o indivíduo à sua própria construção.

De fato, esta é uma necessidade na atualidade, até porque inúmeros são os autores que discutem o fenômeno da pós-modernidade, podendo-se citar nomes como Gilles Lipovetsky (2005), Jean-François Lyotard (1988), Michel Maffesolii (1998), Anthony Giddens (2000), Ulrich Beck (2006), Zygmunt Bauman (2001), dentre outros tantos. Estes trazem que, no contexto atual, apesar da maior aproximação entre os seres humanos, a crise existencial é cada vez maior. Aquilo que começou a ser denunciado no fim do séc. XIX pelos existencialistas e durante o séc. XX pelos psicólogos humanistas tornou-se a norma corrente em toda a sociedade humana; um fenômeno, portanto, não polarizado apenas nos países considerados mais desenvolvidos, mas que envolve todos os grupamentos humanos no globo terrestre.

Em face deste contexto no qual a ciência, inclusive, não mais consegue dar as respostas que deveria dar à sociedade, pois também se encontra em crise, tal como denunciou Edmund
Husserl (2002), o Grupo Paideia se propõe a formar os seus participantes para enfrentarem os dilemas do homem contemporâneo a partir do modelo grego (a Paideia), obviamente atualizado com os dilemas da sociedade pós-moderna.

Que espírito humanista grego era esse? Jaeger foi extremamente preciso ao considerar que:

A sua descoberta do Homem não é a do eu subjetivo, mas a consciência gradual das leis gerais que determinam a essência humana. O princípio espiritual dos gregos não é o individualismo, mas o "humanismo", para usar a palavra no seu sentido clássico e originário. Humanismo vem de humanitas. [...] Significou a educação do Homem de acordo com a verdadeira forma humana, com o seu autêntico ser. Tal é a genuína paideia grega, considerada modelo por um homem de Estado romano. Não brota do individual, mas da idéia. Acima do Homem como ser gregário ou como suposto eu autônomo, ergue-se o Homem como idéia (JAEGER, 2003, p. 14).

De que maneira se dava a Paideia grega? Tal como se encontra relatado nas páginas da obra de Jaeger, bem como nos principais tratados da filosofia clássica grega, como A república, de Platão (2001), a pedagogia do homem grego era centrada em dois princípios: o ensino da ginástica e da música, ou seja, o estímulo ao trabalho do corpo e da mente, para que, ao se desenvolverem ambos, tenha-se o trabalho integral do ser humano.

Aristóteles, ao dedicar o último livro da sua obra Política (1998) para tratar da formação dos jovens para a cidade, destaca, além do estudo da ginástica e da música, também o da gramática como elemento primordial para a formação humana.

Em vista do que foi aqui tratado, a formação do Grupo de Estudos Paideia se traduz no preparo intelectual dos seus integrantes, tanto 
por meio do próprio Grupo de Estudos quanto pelas pesquisas a que cada um dos participantes é estimulado. Além disso, há também o estímulo a que seus integrantes venham a se preparar para sua atuação no mercado de trabalho, bem como ao desenvolvimento do espírito empreendedor dentro de si, tanto pelo desenvolvimento de atividades que revertam em benefício da universidade quanto pela frequência em estágios profissionalizantes ou abertura de um pequeno negócio próprio. Por fim, há ainda o aspecto da responsabilidade social, pois os participantes do Grupo são formados não apenas para construírem uma vida e uma carreira profissional de sucesso, mas para que todo seu crescimento reverta no desenvolvimento da sociedade com um todo, seja no exercício de sua atividade profissional, seja por meio de uma das atividades de extensão promovidas dentro do Grupo.

Conforme Jaeger:

A idéia de educação representava para ele [o povo Grego] o sentido de todo esforço humano. Era a justificação última da comunidade de individualidades humanas. O conhecimento próprio, a inteligência clara do Grego encontravam-se no topo do seu desenvolvimento [...] E foi sob a forma de Paideia, de "cultura", que os Gregos consideraram a totalidade da sua obra criadora em relação aos outros povos da Antiguidade de que foram herdeiros (JAEGER, 2003, p. 7).

Resta assim devidamente caracterizada a visão de Paideia do Grupo, a necessidade de que o participante venha a se autoconhecer para, a partir disso, se lançar a buscar conhecer não somente a si, mas aos outros e ao mundo que o circunda (dimensão intersubjetiva), trabalhando para a contínua melhoria da civitas da comunidade de homens reunidos com esse objetivo, viver bem e venturosamente, tal como dissera Aristóteles (1998, p. 221).

Apresentados os pressupostos basilares da proposta de formação do Grupo Paideia, no próximo momento se tratará sobre o projeto de criação do Grupo de Estudos Paideia no campus de São José e do modo como ele foi desenvolvido.

\section{A criação do grupo de estudos Paideia - campus de São José}

Conforme se demonstrou acima, todas as atividades que atualmente são executadas no Grupo de Pesquisa e Extensão Paideia têm como ponto de origem o Grupo de Estudos em Filosofia e, a partir de 2009, os dois novos grupos de estudos que foram criados, o Grupo de Estudos em Literatura e Sociedade e o Grupo de Estudos em Psicologia Organizacional.

Em razão desse fato, a proposta deste projeto de extensão foi constituir um Grupo de Estudos de Filosofia, nos moldes daquele criado em Itajaí dentro do campus da Univali de São José, de modo que também pudessem ser atendidos nele os acadêmicos do campus de Biguaçu e da Unidade Universitária do Kobrasol ${ }^{10}$ em razão de sua proximidade.

Assim, em 2009, iniciaram-se os trabalhos em São José em favor da organização do Grupo de Estudos da obra Paideia, desde o contato com as autoridades administrativas da Univali, passando pela a divulgação do Grupo de Estudos dentro da universidade e o convite dos interessados para participarem das reuniões.

Os bolsistas que participaram do projeto tinham em mente o quão difícil seria começar do "zero" um projeto como o Grupo Paideia, que, para tomar o corpo que apresenta atualmente em Itajaí e receber o reconhecimento

${ }_{10}$ Nome de um dos principais bairros do Município de São José. 
tanto por parte da instituição quanto por parte dos acadêmicos, foi sendo gestado pelas diversas atividades lá empreendidas ao longo dos seus dez anos de existência.

Em São José, ao contrário, o único registro histórico de atividades foi, no ano de 2007, a apresentação da peça teatral Agamemnon, uma interpretação da tragédia de mesmo nome de Ésquilo para o evento Opção Profissional por Área (OPA $)^{11}$.

Com exceção deste fato, a outra ligação que havia entre o campus de São José e o Grupo Paideia era um dos professores do corpo docente, que foi integrante do Grupo de Estudos na época em que se estudava a Paideia, professor este que inclusive auxiliou na divulgação das atividades que viriam a ser realizadas em São José.

Em 2 de abril de 2009 foi realizado o primeiro encontro do Grupo de Estudos de Filosofia em São José. A essa reunião compareceram três acadêmicos, além da bolsista do projeto e um acadêmico participante do Grupo Paideia de Itajaí. Nessa data foi apresentado o projeto do Grupo Paideia, qual o seu objetivo, o que ele faz, que parcerias realiza e, acima de tudo, a proposta de estudos para o Grupo, apresentando-se aos participantes a obra Paideia.

A partir de então, os encontros do grupo começaram a ser realizados todas as quintas-feiras, no período das 18:00 às 19:0012. A média de presença nesse primeiro ano variou entre cinco e seis participantes, e durante esse período trilhou-se o caminho do livro primeiro da obra, que principia com a paideia dos poetas gregos, passa pela organização das principais cidades gregas, pelo nascimento da Filosofia, até chegar ao período das principais revoluções políticas nas polis gregas.

Comentário interessante a ser feito neste momento é sobre o modo como é realizada a abordagem dos grupos de estudos do Grupo Paideia. Na sistemática dos grupos de estudos são levantadas discussões acerca dos temas trabalhados no livro em análise, seguindo a ordem utilizada pelo autor da obra.

Assim, em cada encontro são delimitados os temas de pesquisa acerca dos estudos e é delegada a um dos participantes a tarefa de preparar o material para a discussão no próximo encontro. Desse modo garante-se que todos participem das atividades, bem como se responsabilizem pelo momento de compartilhamento dos conhecimentos adquiridos. Em Itajaí, os professores coordenadores do projeto participam como facilitadores do conteúdo, conduzindo os debates e trazendo os esclarecimentos necessários sobre a temática abordada. Para o projeto do grupo de estudos em São José, este papel de facilitadores ficou a cargo dos bolsistas que conduziram o projeto, que já tinham experiência tanto no conteúdo da obra quanto na participação em grupos de estudos.

Nessa lógica de trabalho, a cada encontro se progredia no texto do livro, às vezes de maneira mais acelerada, outras nem tanto, em razão da discussão de um ponto específico. Importante salientar que o grupo de estudos não é apenas um espaço de formação intelectual, estritamente filosófica. Tendo em vista a visão de formação humana, os textos servem muito mais para incitar à reflexão sobre a situação da nossa vivência no aqui e no agora, no dasein, como diria Heidegger, do que simplesmente para compreender o que disse determinado autor.

Portanto, ao se estudar alguma temática da obra, abre-se a discussão sobre de que modo aquele assunto diz respeito à nossa vivência hoje e de que modo se pode então agir da maneira mais adequada em determinada situação. É por esta iniciativa que os grupos de estudos são o primeiro momento em que a Paideia do grupo é implementada. Não se traz a linha de interpretação, ou a resposta ao aluno, estimula-se para que este busque saber sobre o fato com o qual

\footnotetext{
${ }^{11}$ Evento promovido anualmente pela Univali, no qual são divulgados para a comunidade os cursos que oferece.

12 Horário que antecede as aulas realizadas no período noturno no campus, que ocorrem das 19:00 às 22:30.
} 
se depara na existência, a ter uma atitude não somente de conhecer algo, mas de ser alguém que incessantemente busca entender como as coisas são e agir do modo adequado, alguém que aprende a aprender, como disse Demo (1995, p. 30). Neste sentido:

O aprender faz parte do aprender a aprender. Mas o processo educativo se manifesta caracteristicamente na habilidade de refazer crítica e criativamente o conhecimento disponível, superando a condição de cópia meramente aprendida. Aprender é coisa do discípulo, que tem em vista imitar o mestre. Aprender a aprender é típico de mestre, que busca ser sujeito autônomo e formular proposta própria.

A principal razão de se utilizar a filosofia é que ela permite que o indivíduo possa estender seu ponto de vista para além do que é demonstrado. Conforme considera Alves (1991, p. 91): "[...] a filosofia é uma atividade que se dedica a questionar os cenários, as estruturas categoriais, os pressupostos comumente aceitos sem exame."

Portanto, pela filosofia se fomenta a capacidade crítica como um meio de transformação responsável e coerente, primeiramente de si mesmo e em seguida de tudo aquilo que é relativo ao indivíduo, para que então se possa falar em transformação da sociedade. Assim, conclui Alves (1991, p. 93): "A tarefa filosófica implica duas fases: a primeira, crítica, a segunda, criativa". Portanto, primeiro se adquire a compreensão sobre algo em todas as suas dimensões, para que então se possa deliberar sobre as possibilidades de transformação desse dado que foi apreciado.

O grupo de estudos, apesar de ser o grande objetivo deste projeto, não foi a única atividade realizada durante todo o projeto. Além dos encontros semanais, foram feitas reuniões com a com a Secretaria Municipal de Educação de São José e com a equipe da Comissão do Bem Estar do Menor de Itajaí (Combemi) - Ação para a Juventude ${ }^{13}$, entidade privada sem fins lucrativos que há 38 anos atende a jovens e adolescentes do Município de Itajaí, com cursos destinados à qualificação profissional básica.

A aproximação com a Combemi rendeu a realização de quatro eventos no segundo semestre de 2009, denominados "Semana Paideia", o primeiro entre 24 e 28 de agosto, o segundo entre 31 de agosto e 4 de setembro, o terceiro entre 8 e 11 de setembro e a quarta Semana Paideia, entre 14 e 18 de setembro.

Durante esse período, a bolsista do projeto realizou palestras com os alunos do Combemi sobre o mercado de trabalho atual e a importância da formação do jovem para se inserir nele de maneira adequada. As palestras realizadas durante as quatro Semanas Paideia atingiram um número de aproximadamente 50 alunos do Combemi, rendendo um feedback muito positivo sobre os resultados obtidos durante os eventos.

Quanto à Secretaria de Educação de São José, apesar de se ter estabelecido contato com o órgão e apresentado um projeto de realização de palestras nos mesmos moldes daquelas realizadas com o Combemi em Itajaí, não houve disponibilidade de horários para a realização do projeto durante o ano de 2009, sendo, portanto um ponto no qual este projeto não alcançou sucesso.

No ano de 2010, por sua vez, em razão de os dois bolsistas que atuaram no projeto estarem em período de conclusão de curso, encarregados com as demais atividades correlatas a esse período, como o trabalho de conclusão de curso, as atividades acabaram se limitando à realização do grupo de estudos semanal.

Nos encontros, a média foi de 7 a 8 participantes por encontro, e durante esse ano a leitura da obra avançou pelos livros segundo e

$\overline{13}$ Mais informações podem ser obtidas no endereço: <http://www.combemi.com.br $>$. 
terceiro da Paideia, um compreendendo os principais tragediógrafos e comediógrafos gregos, bem como os sofistas, e o outro sobre Sócrates, alcançando-se até a parte sobre os diálogos menores de Platão, sem entrar na análise sobre a República que ocupa, onde se concluiria dito livro.

Além do grupo semanalmente, também eram organizados encontros com os participantes para discutir sobre os seus temas de pesquisa, orientando-os à produção científica $e$ estimulando-os à participação em eventos nesse sentido.

Como resultado desse trabalho, em novembro de 2010 foi organizada a Semana de Iniciação Científica do Grupo Paideia em São José, oportunidade em que os participantes do grupo puderam apresentar os resultados de suas pesquisas individuais ou de seus trabalhos feitos com relação à obra Paideia. Este evento contou com a participação e presença de todos os acadêmicos que assiduamente participavam das reuniões do grupo.

Este é o relato das atividades executadas pelo Grupo de Estudos Paideia durante os anos de 2009 e 2010. Com base nessas informações, torna-se possível analisar os resultados do projeto, conforme se fará a seguir.

\section{Considerações finais}

O presente artigo teve por objetivo expor os resultados da proposta de ampliação das atividades do Grupo de Pesquisa e Extensão Paideia, até então atuante nos limites do campus de Itajaí, para os campi e unidades universitárias da Grande Florianópolis.

Cientes de que a simples transposição de tudo aquilo que já existe em Itajaí para o novo espaço não seria a atitude mais recomendada, propôs-se começar as atividades, em São José, do mesmo modo que foi feito em Itajaí, a partir da realização de um grupo de estudos da obra Paideia: a formação do homem grego.

Tal como restou demonstrado, dito grupo de estudos foi devidamente organizado com encontros regulares durante esses dois anos de execução do projeto, nos quais, obviamente, não foi possível concluir os estudos de uma obra que conta com mais de 1.500 páginas, mas foi possível avançar muito na leitura e, muito mais do que isso, estimular nos participantes do grupo uma nova atitude em relação às próprias vidas e ao modo de ver o mundo que os circunda.

Portanto, como resultado direto deste trabalho pode-se destacar a realização do grupo de estudos, como se pretendeu desde o início, como meio de se estabelecerem as bases para que novas atividades venham a ser desenvolvidas, beneficiando não somente a comunidade acadêmica da Univali na Grande Florianópolis, mas a própria sociedade de Biguaçu, São José, Palhoça e Florianópolis.

Houve esforços para já se iniciar uma nova fase de execução do projeto, com a implementação de cursos na rede escolar municipal, apesar de terem restado frustrados em um primeiro momento. Contudo, estando organizado o grupo de estudos, certamente os atuais participantes, ou os novos que venham a se tornar bolsistas do projeto, se responsabilizarão por tanto.

Os dois bolsistas envolvidos na execução deste projeto de extensão já concluíram seu curso de graduação em Direito, já se encontram inseridos dentro do mercado de trabalho, mas deixaram uma semente dentro da universidade, uma atividade que não dependerá mais de ambos para ser realizada e que, com certeza, poderá beneficiar tantas outras pessoas do mesmo modo que a eles durante os seus cinco anos de graduação, participando do Grupo Paideia em Itajaí.

Fica o exemplo do projeto de formação do Grupo de Pesquisa e Extensão Paideia não somente para toda a comunidade acadêmica da Univali, mas para todas as instituições de ensino superior que buscam fazer da vida universitá- 
ria um momento de preparação daqueles que conduzirão o nosso país à construção de uma sociedade livre, justa e solidária, tal como preconizado na Constituição da República Federativa do Brasil de 1988, bem como para aqueles que buscam ver os oito objetivos para o milênio estabelecidos com sucesso (ESPER, 2010).

\section{REFERÊNCIAS}

ALVES, Rubem. Conversas com quem gosta de ensinar. 26. ed. São Paulo: Cortez; Autores Associados, 1991.

ARISTÓTELES. Política. Tradução de António Campelo Amaral e Carlos de Carvalho Gomes. Lisboa: Vega, 1998. (Edição Bilíngue).

BAUMAN, Zygmunt. Modernidade líquida. Tradução de Plínio Dentzien. Rio de Janeiro: Jorge Zahar, 2001.

BECK, Ulrich. La sociedad del riesgo global: amor, violencia y guerra. 2. ed. Madrid: Siglo XXI, 2006.

BRASIL. Constituição (1988). Constituição da República Federativa do Brasil. Disponível em: < http://www.planalto. gov.br/ccivil_03/constituicao/constitui\%C3\%A7ao.htm>. Acesso em: 13/01/2011.

COMBEMI. Disponível em: <http://www.combemi.com. br/index.php?option $=$ com_content $\&$ view $=$ article $\&$ id $=1$ $2 \&$ Itemid $=116>$. Acesso em: 13/02/2011.

DEMO, Pedro. Educação e qualidade. 2. ed. Campinas: Papirus, 1995.

ESPER, Aulia. O oitavo objetivo do milênio e o papel dos futuros líderes: a importância da criação de um programa de formação de jovens lideranças políticas e sociais. Revista Filosofia do Direito e Intersubjetividade, v. 4, 2010. Disponível em: <http://www.univali.br/modules/system/ stdreq. aspx?P $=1739 \& \mathrm{VID}=$ default $\& S \mathrm{SI}=38708511$ $5430999 \& S=1 \& A=$ closeall $\& C=33258>$. Acesso em: $13 / 01 / 2011$.

GIDDENS, Anthony. O mundo na era da globalização. Tradução de Saul Barata. 6. ed. Lisboa: Presença, 2000.

HEIDEGGER, Martin. Ser e tempo. 15. ed. Tradução de Marica Sá Cavalcante Schuback. Petrópolis: Vozes, 2005.

HUSSERL, Edmund. La crisi delle scienze europee e la fenomenologia trascedentale: per un sapere umanistico. Traduzione di Enrico Filippini. Milano: Net, 2002.

JAEGER, Werner Wilhelm. Paidéia: a formação do homem grego. 4. ed. São Paulo: Martins Fontes, 2003.
KIERKEGAARD, Søren. Diário de um sedutor; Temor e tremor; O desespero humano. Tradução de Carlos Grifo; Maria José Marinho; Adolfo Casais Monteiro. 3. ed. São Paulo: Nova Cultural, 1988. (Os pensadores).

LIPOVETSKY, Gilles. A era do vazio: ensaios sobre o individualismo contemporâneo. Tradução de Therezinha Monteiro Deutsch. Barueri: Manole, 2005.

LYOTARD, Jean-François. O pós-moderno. Tradução de Ricardo Corrêa Barbosa. Rio de Janeiro: José Olympio, 1988.

MAFFESOLI, Michel. O tempo das tribos: o declínio do individualismo nas sociedades de massa. Tradução de Maria de Lourdes Menezes. 2. ed. Rio de Janeiro: Forense, 1998. (Ensaio \& Teoria).

MASLOW, Abraham. Introdução à psicologia do ser. Tradução de Álvaro Cabral. Rio de Janeiro: Eldorado, 199 ?.

MAY, Rollo. O homem à procura de si mesmo. Tradução de Aurea Brito Weissenberg. 33. ed. Petrópolis: Vozes, 200 ?.

NIETZSCHE, Friedrich Wilhelm. Assim falou Zaratustra: um livro para todos e para ninguém. 9. ed. São Paulo: Civilização Brasileira, 1998.

PLATÃO. A república. 9. ed. Tradução de Maria Helena da Rocha Pereira. Lisboa: Fundação Calouste Gulbenkian, 2001.

ROGERS, Carl. Tornar-se pessoa. Tradução de Manuel José do Carmo Ferreira. 3. ed. São Paulo: Martins Fontes, 1990.

SARTRE, Jean Paul. Ser e o nada: ensaio de ontologia fenomenológica. Tradução de Paulo Perdigão. 5. ed. Petrópolis: Vozes, 1997.

VIS INSTITUTO. Disponível em: < http://www.visconsultoria.com.br/index.php?option $=$ com_content\&task $=$ view $\& \mathrm{id}=25 \&$ Itemid $=36>$. Acesso em: $13 / 02 / 2011$.

Texto recebido em 17 de fevereiro de 2011. Texto aprovado em 24 de fevereiro de 2011. 